\title{
AVANT LANFRANC. UN RÉEXAMEN DE LA CARRIÈRE DE MAUGER, ARCHEVÊQUE DE ROUEN (1037-1054/55) ${ }^{1}$
}

Le fils du duc Richard II et de sa deuxième femme Papie, l'archevêque de Rouen Mauger, fut, avec son frère Guillaume d'Arques, comte de Talou, parmi les plus puissants dans le duché pendant la minorité de Guillaume le Bâtard. Néanmoins, son épiscopat prit fin avec sa déposition, et les historiens modernes ont longtemps considéré Mauger comme un évêque non réformateur, un pré-grégorien, l'antithèse de Lanfranc, réputé, à juste titre, pour ses largesses, pour ne s'intéresser qu'à son profit personnel et pour ses spoliations ${ }^{2}$. Cependant, certains indices suggèrent que Mauger a été traité injustement, non seulement par des chroniqueurs contemporains, mais aussi par des spécialistes modernes, qui répètent volontiers les histoires scandaleuses de leurs homologues médiévaux. Mauger devint archevêque pendant une des périodes les plus troublées de l'histoire du duché, mais il semble néanmoins avoir pris des mesures pour stabiliser et renforcer les affaires ecclésiastiques et laïques dans la région. C'est au cours de son archiépiscopat que la Trêve de Dieu a été introduite pour la première fois en Normandie, et sous son autorité que le premier concile normand de la réforme a été convoqué. De plus, Mauger accueillit les autres réformateurs dans le duché, comme Richard de Saint-Vanne. L'archevêque de Rouen contribua également à la croissance des abbayes normandes, y compris la nouvelle fondation du Bec, qui accueillit Lanfranc peu après la dédicace de l'église abbatiale par lui-même. Les actes archiépiscopaux, une source méconnue, offrent une autre perspective du caractère de Mauger et révèlent un homme qui non seulement s'est consacré au bien-être de son Église, mais encore s'est intéressé à la vie spirituelle de la ville qui était sous son autorité.

Les sources narratives sont principalement responsables de la réputation négative de Mauger. Le récit le plus long et le plus accablant est celui de Guillaume de Poitiers. Écrit quelques décennies après la déposition de Mauger, il raconte comment

1. Je tiens à remercier le Professeur Véronique Gazeau d'avoir corrigé le français de la version primitive de cet article. Je remercie tout particulièrement les conférenciers et les participants du colloque «Autour de Lanfranc» pour leurs observations et leurs suggestions très constructives. Je demeure seul responsable des fautes ou inexactitudes qui restent.

2. Voir P. Bouet, M. Dosdat, «Les évêques normands de 985 à 1150 ", in Les évêques normands du XIe siècle (Actes du colloque de Cerisy-la-Salle, 30 septembre-3 octobre 1993), P. Bouet et F. Neveux (dir.), Caen, Presses universitaires de Caen, 1995, p. 19-20. 
l'archevêque «ne s'appliquait pas à gouverner sa propre vie» et comment il gérait son église comme «le maître le plus dur, [et] le spoliateur le plus avide». Ce récit contient la première accusation mensongère sur la carrière de l'archevêque, c'est-àdire la déclaration qu'il «ne fut revêtu du pallium... le pontife romain qui en dispose le lui refusa en raison de son indignité ${ }^{3}$. Cette accusation n'est pas fondée, puisque la réforme papale n'avait guère commencé à cette époque, et le pape n'était pas en position de revendiquer le droit de conférer ce vêtement ${ }^{4}$. Néanmoins, ces charges sont rapidement devenues partie d'une damnatio memoriae qui a suivi Mauger tout au long des siècles. L'autre grande chronique normande du $\mathrm{XI}^{\mathrm{e}}$ siècle, les Gesta Normannorum ducum de Guillaume de Jumièges, n'a que quelques mots à dire sur l'archevêque, tout aussi négatifs que ceux de Guillaume de Poitiers ${ }^{5}$. Aucun des deux auteurs ne donne les sources de leurs accusations, mais la mauvaise image de Mauger avait déjà une existence à la cathédrale de Rouen avant 1067. La Chronique métrique sur les archevêques, qui fut probablement composée à l'époque de Maurille (10551067), premier prélat réformateur à Rouen et le successeur de Mauger, condamne ce dernier parce qu' «il ne fut noble par aucune action ${ }^{6}$. Les Actes des archevêques de Rouen, qui furent probablement composés à l'époque de Jean d'Ivry (1067-1079), successeur de Maurille, rapportent que Mauger «fut élevé dans l'enfance» et qu' «il distribua d'une façon puérile les ornements de l'église et d'autres bénéfices » ${ }^{7}$. On ignore dans quelle mesure Guillaume de Poitiers et Guillaume de Jumièges ont pu connaître et utiliser ces deux textes, mais Orderic Vital se reposait certainement sur ces sources rouennaises tout en faisant son portrait de Mauger, incorporant même la Chronique métrique dans son histoire ecclésiastique ${ }^{8}$.

Parmi les autres chroniqueurs du XII ${ }^{\mathrm{e}}$ siècle, seuls Guillaume de Malmesbury et Wace consacrent quelques lignes à l'archevêque. Le récit de Guillaume est semblable à ceux du $\mathrm{XI}^{\mathrm{e}}$ siècle, sauf qu'il cite des crimes spécifiques de Mauger, comme son amour du combat de coqs et de la chasse ${ }^{9}$. Quant à Wace, ce sont les dernières années de la vie de Mauger qui l'intéressent. L'archevêque fut relégué à Guernesey après sa déposition, et Wace, originaire de Jersey, était sans doute bien informé de ce qui se passait dans les îles Anglo-Normandes, ou au moins de leurs traditions orales. Mais l'histoire qu'il raconte ne flatte pas l'archevêque et inclut des accusations de magie

3. Guillaume de Poitiers, Gesta Guillelmi ducis Normannorum et regis Anglorum, R. Foreville (éd.), Paris, Les Belles Lettres (Les classiques de l'histoire de France au Moyen Âge), 1952, p. 130; Gesta Guillelmi, p. 86.

4. Gesta Guillelmi, p. 88, n. 1 .

5. Gesta Normannorum ducum, t. II, p. 130.

6. Rouen, BM, Y. 27 Omont 1405, p. 39; Rouen, BM, Y. 41 Omont 1406, fol. 14v.

7. R. Allen, «The Acta archiepiscoporum Rotomagensium: Study and Edition», Tabularia «Documents", t. IX, 2009, p. 38.

8. OV, t. III, p. 50-94.

9. Malmesbury, Gesta regum Anglorum, t. I, p. 494. 
noire et de folie ${ }^{10}$. En dehors de la Normandie, la mauvaise réputation de Mauger était encore connue au XIV ${ }^{\mathrm{e}}$ siècle à l'abbaye de Saint-Bertin de Sithiu ${ }^{11}$.

Mais si on démontre que plusieurs des critiques lancées contre l'archevêque sont injustes ou sans fondement, l'accusation que Mauger fut trop jeune pour être archevêque semble bien fondée sur des faits réels. David Douglas a montré que Richard II a vraisemblablement épousé Papie "peu après» la mort de sa première femme Judith en juin $1017^{12}$. Si Mauger a été conçu dans les premiers mois de l'union, il serait né au printemps 1018, ce qui signifie qu'il serait devenu archevêque autour de son dixneuvième anniversaire. Dans une autre tradition rapportée par Robert de Torigni, sur laquelle le professeur Douglas n'a pas fait de commentaire, le mariage est placé sous l'année $1024^{13}$. Si cela était vrai, Mauger aurait pu devenir archevêque dès l'âge de treize ans. Bien que scandaleuses, ces pratiques ne sont pas inconnues dans le duché, puisque Odon de Conteville fut élu évêque de Bayeux au même âge, environ ${ }^{14}$.

Si Mauger fut élu à cet âge, cela explique peut-être la nature viscérale des attaques lancées plus tard contre lui. Or il semble que l'archevêque ne monta pas sur le siège de Rouen sans être partiellement préparé. Si l'on en croit les éditeurs de la Gallia Christiana, qui disposaient peut-être de sources aujourd'hui disparues, le jeune Mauger fut moine à Fécamp ${ }^{15}$. Malheureusement, nous ne savons rien de sa vie à l'abbaye, mais il est possible qu'il ait reçu une formation semblable à celle de son prédécesseur, l'archevêque Robert (989-1037), qui étudia sous la direction d'un maître des arts libéraux à Saint-Ouen de Rouen ${ }^{16}$. Guillaume de Poitiers et Guillaume de Malmesbury parlent de l'érudition de Mauger, et nous reviendrons sur cet aspect de sa carrière. Notons que ses réussites sont d'autant plus remarquables qu'elles sont celles d'un jeune archevêque.

10. Wace, The Roman de Rou, G. Burgess (éd.), Jersey, Société jersiaise, 2002, p. 200.

11. «... ipsum archiepiscopum [Malgerium] deponi procuravit, alio tamen colore quaesito; nam archiepiscopus, generis sui gratia, venationibus et saecularibus actibus, plus justo vacans, ecclesiae suae minus intendebat. Hunc titulum sibi Willermus opposuit, et quod suae juventutis gaudia nimis insequebatur; eumque deponi fecit» (Jean d'Ypres, Chronicon Monasterii Sancti Bertini, in RHGF, t. XI, Paris, Académie des Inscriptions et Belles-Lettres, 1876, p. 382).

12. D.C. Douglas, "Some Problems of Early Norman Chronology», EHR, t. LXV, 1950, p. 292.

13. Chronique de Robert de Torigni, abbé du Mont Saint-Michel, suivie de divers opuscules historiques de cet auteur et de plusieurs religieux de la même abbaye, L. Delisle (éd.), Rouen, A. Le Brument et C. Métérie (Société de l'histoire de Normandie), 1872-1873, 2 vol., t. I, p. 32.

14. D. Bates, "The Character and Career of Odo, Bishop of Bayeux (1049/50-1097)", Speculum, t. L, 1975, p. 2 ; L. Musset, «Un prélat du XI ${ }^{\mathrm{e}}$ siècle, Odon de Bayeux", Art de Basse-Normandie, t. LXXVI, 19781979, p. 13.

15. «Richardi II Normanniae ducis ex Papia secunda conjuge filius Malgerius patruum excepit, antea monachus Fiscannensis... », in GC, t. XI, col. 28. Heinrich Böhmer a posé l'hypothèse que Mauger était un élève de l'école de Guillaume de Volpiano: H. Böhmer, Kirche und Staat in England und in der Normandie im XI. und XIII. Jahrhundert, Leipzig, Dieterich, 1899, p. 11.

16. "The Cathedral Miracles of Romanus ", in F. Lifshitz, The Norman Conquest of Pious Neustria: Historiographic Discourse and Saintly Relics, 684-109o, Toronto, Pontifical Institute of Mediaeval Studies (Studies and texts; 122), 1995, p. 268. 
Toutefois, les premières années de la carrière de Mauger ne se déroulèrent pas sans difficultés. La mort de Robert le Magnifique en 1035 et celle de l'archevêque Robert deux ans plus tard provoquèrent un vide politique rapidement comblé par des sanglantes vendettas qui déchirèrent l'aristocratie normande ${ }^{17}$. Selon Michel de Boüard, ces circonstances chaotiques montrent que Mauger n'avait pas l'expérience ni l'autorité de son prédécesseur ${ }^{18}$, mais ces actions violentes étaient caractéristiques de la période de transition qui suivait le décès d'un duc $^{19}$. De plus, si les contemporains de Mauger ont tiré profit de ses faiblesses, l'archevêque retrouva vite son autorité. David Douglas a constaté comment les sources diplomatiques démontrent que Mauger tint un rôle de premier plan dans la vie politique normande, et comment, aux côtés de son frère Guillaume d'Arques, il occupa la première place dans la hiérarchie de la cour ducale ${ }^{20}$. C'est aussi durant ces premières années que les carrières de Lanfranc et de Mauger commencèrent à se croiser. À la fin des années 1030, et en dépit du chaos qui est censé avoir assailli le duché, le futur archevêque de Cantorbéry choisit de venir en Normandie, où il enseigna à Avranches ${ }^{21}$. Quelques années plus tard, Mauger confirma les premières acquisitions de l'abbaye du Bec, dont l'église primitive fut consacrée par l'archevêque ${ }^{22}$. Par ces actes, l'archevêque joua non seulement un rôle important dans la vie de l'une des plus célèbres abbayes de Normandie, mais il eut également l'occasion d'influencer indirectement la vie de Lanfranc, car c'est au Bec que ce dernier devint moine vers $1042^{23}$.

C'est aussi à cette époque que l'archevêque commença à s'intéresser au mouvement de réforme. Selon Hugues de Flavigny, quand Richard de Saint-Vanne vint en Normandie en 1041-1042, l'archevêque Mauger et son clergé auraient prêté grande attention à ses conseils ${ }^{24}$. L'abbé de Verdun convainquit également l'archevêque d'enrichir la bibliothèque de sa cathédrale d'un ouvrage liturgique, et ce «livre commun » (liber communis), qui fut enchaîné derrière l'autel majeur, est peutêtre le bréviaire «quod vocatur Ricardus» qui est enregistré dans un catalogue du

17. D.C. Douglas, William the Conqueror: the Norman Impact upon England, Londres, Eyre and Spottiswoode, 1964, p. 40-52.

18. M. de Boüard, Guillaume le Conquérant, Paris, Librairie Arthème Fayard, 1984, p. 104.

19. Sur les circonstances après la mort du Conquérant, voir C.W. David, Robert Curthose, Duke of Normandy, Cambridge (Mass.), Harvard University Press, 1920, p. 43-44; W. Aird, Robert Curthose, Duke of Normandy, c. 1050-1134, Woodbridge, The Boydell Press, 2008, p. 104-117.

20. D.C. Douglas, William the Conqueror..., p. 40-41.

21. Il semble que Lanfranc ait visité Avranches pour accéder à la bibliothèque du Mont Saint-Michel (Gibson, Lanfranc, p. 20-21; Cowdrey, Lanfranc, p. 10).

22. Fauroux, $\mathrm{n}^{\circ}$ 98. La dédicace, située traditionnellement le 23 février 1041 (A.-A. Porée, Histoire de l'abbaye du Bec, Évreux, Imprimerie de C. Hérissey, 1901, 2 vol., t. I, p. 43, n. 3), est aujourd'hui remise en question par les historiens. Voir l'article de Jean-Hervé Foulon dans ce volume.

23. Gibson, Lanfranc, p. 25 ; Cowdrey, Lanfranc, p. 12.

24. «... aecclesiam Rotomagensem cum praesule sedis ipsius et clero, ejus gauderet decorari doctrina» (Hugues de Flavigny, Chronicon, G.H. Pertz (éd.), Hanovre, 1848 (MGH, Scriptores; 8), p. 402). 
$\mathrm{XII}^{\mathrm{e}}$ siècle $^{25}$. Nous ne savons pas si Richard influa sur la décision de Mauger de tenir un concile de réforme, mais quatre années après la visite du réformateur, l'archevêque de Rouen convoqua une telle réunion ${ }^{26}$. Ce concile, qui eut lieu avant 1046 et auquel ne se rendirent que deux évêques, est généralement considéré comme reflétant les désordres qui troublaient l'Église normande à cette époque et l'incompétence avec laquelle Mauger aurait géré sa province ${ }^{27}$. Mais David Bates a récemment constaté comment la lettre synodale, qui précède les dix-neuf canons, présente une solide condamnation des maux de l'époque et en particulier de la simonie. L'autorité canonique est également bien déployée, et en critiquant les faiblesses des dirigeants laïques, l'archevêque assumait un rôle traditionnel des évêques depuis l'époque carolingienne ${ }^{28}$.

L'étude précise de cette lettre montre aussi que beaucoup de ses phrases sont empruntées à une grande variété de sources, y compris les Moralia in Job de Grégoire le Grand, les canons de trois conciles ibériques du haut Moyen Âge et même peutêtre Cicéron ${ }^{29}$. Il faut tout d'abord constater que la découverte de ces allusions a des conséquences énormes pour la compréhension de l'archevêque Mauger. Les citations empruntées aux conciles ibériques, par exemple, révèlent une connaissance spécialisée du droit canonique, et elles trahissent l'image d'un archevêque loin de celle donnée par des chroniqueurs comme Guillaume de Poitiers. Lanfranc aurait certainement été impressionné par ces allusions parce que, comme Mauger, l'archevêque de Cantorbéry fit référence plus tard au concile de Braga pendant le concile de Londres, qui fut convoqué en $1075^{30}$.

On ignore malheureusement comment Mauger a eu accès à ces textes spécialisés, mais un certain nombre de possibilités se présentent. Deux des trois conciles ibériques, par exemple, se trouvent dans les Décrétales Pseudo-Isidoriennes ${ }^{31}$. Les plus anciennes copies normandes de ce texte ne remontent qu'au XII siècle $^{32}$, mais c'est à partir du pseudo-Isidore que Lanfranc avait constitué une collection de textes canoniques appelée Collectio Lanfranci. La plus ancienne copie de ce recueil provient

25. Rouen, BM, Y. 27 Omont 1405, p. 128. Sur l'association de ce livre avec Richard de Saint-Vanne, voir M. de Boüard, «Sur les origines de la Trêve de Dieu en Normandie», Annales de Normandie, t. IX, 1959, p. 175.

26. Sacrosancta concilia ad Regiam editionem exacta, P. Labbé (éd.), Paris, 1671-1672, 17 vol., t. IX, col. 10471050.

27. D. Bates, Normandy before 1066, Londres, Longman, 1982, p. 198.

28. D. Bates, "The Conqueror's Adolescence», ANS, t. XXV, 2003, p. 11.

29. Sur ces allusions, voir l'édition critique de la lettre ci-dessous (annexe I).

30. Councils and Synods, t. II, p. 612.

31. Pseudo-Isidore, Collectio decretalium, in PL, t. CXXX, col. 427-430 et 565-572. La meilleure édition critique de la Collectio est disponible en ligne: http://www.pseudoisidor.mgh.de.

32. S. Williams, Codices Pseudo-Isidoriani: a Palaeographical-Historical Study, New York, Fordham University Press (Monumenta iuris canonici; 3), 1971, p. 6-7, 20-21, 29-30, 42. L'édition numérique de la Collectio apporte quelques corrections aux provenances manuscrites proposées par S. Williams (voir «Handschriftenverzeichnis»). 
de l'abbaye du $\mathrm{Bec}^{33}$, et bien que ce manuscrit fût rédigé après 1059, il est probable que Lanfranc enseignait déjà le droit canonique à l'école abbatiale avant cette date ${ }^{34}$. Bien sûr, il est impossible de dire si le rédacteur de la lettre synodale a eu connaissance de Lanfranc et de son milieu, mais il semble que derrière ces allusions se cache une influence extra-rouennaise. En effet, le plus ancien inventaire de la bibliothèque de la cathédrale rouennaise, qui fut rédigé dans le premier tiers du XII ${ }^{e}$ siècle, mentionne des textes que l'on ne retrouve pas dans la lettre synodale ${ }^{35}$. De plus, bien que l'abbaye voisine de Saint-Ouen de Rouen ait possédé plus tard une collection imposante de manuscrits, ce n'est pas avant la deuxième moitié du $\mathrm{XI}^{\mathrm{e}}$ siècle que l'abbé Nicolas commença à agrandir la bibliothèque abbatiale ${ }^{36}$. En revanche, la bibliothèque de l'abbaye de Fécamp, où Mauger était moine, comptait au XI siècle non seulement une copie du travail de Grégoire le Grand, mais aussi une collection de diverses pièces de droit canonique ${ }^{37}$. L'un de ces manuscrits se trouve encore à la Bibliothèque nationale de France (Paris, BnF, lat. 3182), mais cette collection de canons ne contient malheureusement aucun des conciles ibériques connus de l'archevêque Mauger ${ }^{38}$.

Quant au concile de Rouen lui-même, l'archevêque rédigea plusieurs canons contre les maux de l'Église, en particulier la simonie. Mauger réalisa que la vente des offices ecclésiastiques était la forme la plus grave de la corruption dans l'Église, et dans une tentative de résoudre ce problème, le concile interdit la vente des évêchés et celle des abbayes, le transfert des évêques d'un diocèse à un autre et l'invasion par un évêque, un abbé, un archidiacre, un clerc ou un prêtre du bénéfice d'un autre ${ }^{39}$. Le concile prit également le temps de régler certains aspects des sacrements et interdit la vente du chrême ou le paiement du baptême. Certes deux évêques seulement furent présents à ce concile, dont l'un occupait son siège par un échange ${ }^{40}$, contrairement

33. Il s'agit du célèbre manuscrit de Trinity College de Cambridge (B. 16. 44). L'étude fondamentale sur la Collectio est celle de Z.N. Brooke, The English Church and the Papacy from the Conquest to the Reign of John, Cambridge, Cambridge University Press, 1931, p. 57-83. Pour une bibliographie des travaux ultérieurs, voir L. Kéry, Canonical Collections of the Early Middle Ages (ca. 40o-1140): a Bibliographical Guide to the Manuscripts and Literature, Washington, DC, The Catholic University of America Press, 1999, p. 239-243.

34. Sur cette question, voir M. Philpott, Archbishop Lanfranc and Canon law, thèse de doctorat, Université d'Oxford, 1993, 2 vol., 390 p. (dactyl.), t. I, p. 42-87.

35. Rouen, BM, Y. 27 Omont 1405, p. 128.

36. Sur la bibliothèque médiévale de Saint-Ouen, voir G. Nortier, Les bibliothèques médiévales des abbayes bénédictines de Normandie: Fécamp, Le Bec, Le Mont Saint-Michel, Saint-Évroul, Lyre, Jumièges, SaintWandrille, Saint-Ouen, $2^{\mathrm{e}}$ éd., Paris, P. Lethielleux, 1971, p. 183-191.

37. La bibliothèque fécampoise du $\mathrm{XI}^{\mathrm{e}}$ siècle est connue par un inventaire qui fut probablement dressé au temps de Jean de Ravenne (1028-1078): voir Catalogue général des manuscrits des bibliothèques de France. Départements - Tome premier. Rouen, H. Omont (éd.), Paris, Plon, 1886, p. XXIV-XXVI.

38. Voir la notice détaillée dans Bibliothèque nationale. Catalogue général des manuscrits latins. Tome IV ( $n^{\circ} 3014$ à 3277), M.-T. Alverny (éd.), Paris, Bibliothèque nationale, 1958, p. 304-317.

39. Canons 2-5, 11-13, P. Labbé (éd.), Concilia..., t. IX, col. 1048-1049.

40. Il s'agit de Robert, évêque de Coutances (v. 1023-1048), qui échangea son siège avec Herbert, évêque de Lisieux (v. 1023-v. 1046): «De statu hujus ecclesiae ab anno 836 ad 1093 », in GC, t. XI, Instr., col. 218. 
aux règles canoniques. Mais l'existence de la lettre synodale suggère que l'archevêque Mauger espérait que les décrets du concile, qui précédèrent ceux du concile de Reims de presque six années, seraient suivis par tout le clergé normand, et puisque la lettre ne contient aucun mot de reproche à l'endroit des évêques absents, il semble que leur absence fut tolérée ou tout au moins prévue.

C'est aussi pendant l'archiépiscopat de Mauger que la Trêve de Dieu fut introduite dans le duché. Malheureusement, le rôle de l'archevêque de Rouen dans cette entreprise n’a pas toujours été accueilli avec approbation. Pour la spécialiste américaine Felice Lifshitz, le concile de la paix, qui fut tenu à Caen en octobre 1047, a été exploité par la grande rivale de la cathédrale, l'abbaye Saint-Ouen de Rouen, qui apporta les reliques de saint Ouen sur lesquelles les présents jurèrent de respecter la Trêve ${ }^{41}$. Selon Lifshitz, le saint patron de l'abbaye devint vite «le garant de la stabilité politique et sociale normande», tandis que Mauger était non seulement responsable de l'effondrement de l'autorité qui amena l'introduction de la Trêve, mais aussi l'archevêque qui avait laissé la cérémonie être utilisée par un rival pour son propre avantage politique et ecclésiastique $^{42}$. Cependant, la rivalité qui opposa plus tard la cathédrale et l'abbaye Saint-Ouen n'est pas nécessairement manifeste en 1047, et Michel de Boüard constate comment la coalition rouennaise de l'archevêque, de son frère Guillaume et de son neveu Nicolas, abbé de Saint-Ouen, joua un rôle important dans l'introduction de la Trêve de Dieu et dans le rétablissement de l'autorité ducale après la bataille du Val-ès-Dunes ${ }^{43}$.

Et cependant, il faut admettre que cette période de la carrière de Mauger n'a pas été sans problèmes. Au début de 1047, le duc Guillaume avait proposé à Gradulphe, abbé de Saint-Wandrille, d'accepter de devenir le «vicarius» de l'archevêque Mauger ${ }^{44}$. Le sens de ce mot, qui pourrait signifier soit adjoint ou successeur, est difficile à déterminer. Mais le fait que le duc fit une telle proposition suggère qu'il ne se satisfaisait pas de l'archevêque, et au minimum ses actions rappellent qu'il s'apprêtait à rompre avec la politique de ses prédécesseurs, qui avaient coutume de choisir les évêques dans leur parenté, comme le professeur Gazeau l'a constaté ${ }^{45}$. Quoi qu'il en soit, il paraît que Mauger ne contesta pas la proposition, et si le duc avait l'idée de faire Gradulphe seulement l'adjoint de Mauger, il est possible que l'archevêque participa à la prise de décision. L'abbé Gradulphe fut, après tout, un administrateur capable et fut placé à la tête d'une abbaye dont le frère de l'archevêque fut parmi les bienfaiteurs insignes ${ }^{46}$. Notons, en outre, que Lanfranc utilisa les évêques de Rochester comme ses adjoints

\footnotetext{
41. "Miracula sancti Audoeni ", AASS, 24 août, IV, p. 835.

42. F. Lifshitz, The Norman Conquest..., p. 195.

43. M. de Boüard, «Sur les origines de la Trêve... », p. 175-176.

44. Inventio et miracula sancti Vulfranni, J. Laporte (éd.), Rouen - Paris, Société de l'histoire de Normandie (Mélanges; $14^{\mathrm{e}}$ série), 1938, p. 52.

45. Gazeau, Normannia monastica, t. I, p. 282.

46. F. Lot, Études critiques sur l'abbaye de Saint-Wandrille, Paris, Champion, 1913, n 15, 20, 22, 29 et 40.
} 
dans l'administration de l'Église anglaise, bien que la relation entre ces deux évêchés représentât un cas particulier ${ }^{47}$.

En outre, Mauger n'était pas opposé à s'entourer d'hommes remarquables par leur mérite et leur savoir. Le plus célèbre de ceux-ci est l'archidiacre Hugues, qualifié de grammairien ${ }^{48}$. Élève de l'école de Reims, cet Hugues fut un esprit lettré qui occupa une place prééminente dans la ville de Rouen. En juin 1053, par exemple, les moines de Saint-Wandrille, qui apportaient à Rouen les reliques de saint Vulfran, furent reçus par le clergé de la cité, à la tête duquel se trouvait Hugues ${ }^{49}$. Pour Jean-Michel Bouvris, le fait que l'archidiacre exerçait le rôle normalement dévolu à l'archevêque était dû à «l'inconsistant Mauger $»^{50}$, mais c'est tout à fait possible que l'archevêque, dont le frère se rebella au cours de l'été 1053, fût heureux de confier cette tâche à Hugues. En fait, la pancarte de Saint-Léger de Préaux montre que Mauger était prêt à permettre à l'archidiacre d'exercer des fonctions archiépiscopales. Cette charte raconte comment, après que Mauger eut confirmé une donation faite à l'abbaye par Onfroi de Vieilles, ce fut Hugues qui «à voix forte» rappela à ce dernier qu'il fallait respecter son don ${ }^{51}$, un rôle qui, selon d'autres chartes normandes, était normalement dévolu à des évêques ou à des grands laïques ${ }^{52}$. Il semble donc que l'archidiacre Hugues, qui apparaît aux côtés de Mauger plus qu'aucun autre membre du chapitre cathédral ${ }^{53}$, put agir non seulement comme la voix de l'archevêque en sa présence, mais aussi comme son «œil» quand Mauger se trouvait ailleurs. Lanfranc a certainement reconnu l'important rôle joué par Hugues, parce que les archidiacres qui furent rétablis dans chaque diocèse anglais après son arrivée à Cantorbéry agirent de la même façon ${ }^{54}$.

La relation entre Mauger et Hugues le Grammairien rappelle aussi l'érudition de l'archevêque, un élément positif de sa carrière. Selon Guillaume de Poitiers,

47. Cowdrey, Lanfranc, p. 117-119; M. Brett, "The Church at Rochester, 604-1185", in Faith and Fabric: a History of Rochester Cathedral, 604-1994, N. Yates et P.A. Welsby (dir.), Woodbridge, The Boydell Press (Kent history project; 4), 1996, p. 20-22. Je dois cette information à David Johnson et à Julia Barrow.

48. J.-M. Bouvris, "L'école capitulaire de Rouen au XI ${ }^{\mathrm{e}}$ siècle», Études normandes, t. III, 1986, p. 93-97.

49. Inventio et miraculi sancti Vulfranni, p. 58.

50. J.-M. Bouvris, «L'école capitulaire... », p. 96.

51. «... Hugo Grammaticus, Rothomagensis archidiaconus, ex precepto domini Hunfridi, excelsa voce commonuit ut si quis his donis calumniam inferre vellet, libere et in aures omnium protulisset» (Bates, RRAN William $I, \mathrm{n}^{\circ} 217$, p. 692-693).

52. Caen, Musée des Beaux-Arts, coll. Mancel, vol. 303 (VI), fol. 59r-v (il s'agit d'une charte concernant l'église Saint-Pierre de Marigny (dép. Manche, ch.-1.), qui appartenait à l'abbaye d'Aunay); Fauroux, $\mathrm{n}^{\circ} 133$.

53. Fauroux, $\mathrm{n}^{\circ}$ 103, 107; Bates, RRAN William I, $\mathrm{n}^{\circ}$ 217; Cartulaire de l'abbaye de Saint-Père de Chartres, B. Guérard (éd.), Paris, De Crapelet (Collection de documents inédits sur l'histoire de France), 1840, 2 vol., t. I, n XLIX, p. 176-177. Il est possible que la souscription d'un archevêque Hugues dans une charte de Saint-Wandrille (Fauroux, $\mathrm{n}^{\circ}$ 102) soit celle de l'archidiacre Hugues, le scribe ayant écrit "archiepiscopi» plutôt qu' «archidiaconi». Marie Fauroux soutient qu'il s'agit de la souscription d'Hugues, archevêque de Rouen (1130-1164), apposée un siècle après la rédaction supposée.

54. "The Archdeacon and the Norman Conquest», in C.N.L. Brooke, Churches and Churchmen in Medieval Europe, Londres, Hambledon Press, 1999, p. 117-137. 
l'archevêque de Rouen «ne fut pas incapable de pénétrer dans leur sens littéral des mystères de l'Écriture sainte $~^{55}$, tandis que pour Guillaume de Malmesbury il «ne fut pas un médiocre érudit ${ }^{56}$. Malheureusement, il ne subsiste aucun texte théologique, liturgique ou philosophique associé à Mauger, mais un texte diplomatique pourrait révéler une trace de sa connaissance des Écritures et du christianisme ancien. Ce document est une charte par laquelle l'archevêque Mauger et son frère Guillaume donnèrent Perriers-sur-Andelle ${ }^{57}$, avec ses dépendances, à l'abbaye Saint-Ouen de Rouen. Conservé en original aux Archives de la Seine-Maritime, cet acte est écrit à deux mains sur un grand morceau de parchemin ${ }^{58}$. La première, qui se trouve dans la moitié supérieure du parchemin, est en caractères allongés. Cette partie du texte concerne la donation elle-même et fut probablement écrite par un moine de SaintOuen. Les souscriptions apposées au bas de la charte sont en minuscule caroline, de la deuxième main, tandis qu'un acte pris au nom de l'archevêque Mauger est transcrit, de la même minuscule, après lesdites souscriptions. Ce deuxième scribe fut certainement associé à la cathédrale de Rouen, puisque son écriture présente des caractéristiques similaires aux mains qui se trouvent dans d'autres manuscrits du $\mathrm{XI}^{e}$ siècle provenant de la cathédrale, comme le célèbre Livre d'ivoire ${ }^{59}$.

La charte de l'archevêque, qui fut probablement composée avec l'aide de Mauger lui-même, fulmine l'anathème contre ceux qui oseraient enfreindre la donation de Perriers. Comme l'a déjà constaté David Bates, l'anathème se trouve souvent dans les actes de l'archevêque Mauger ${ }^{60}$, mais cette malédiction est la plus sévère qui ait été lancée par un évêque normand du $\mathrm{XI}^{\mathrm{e}}$ siècle. Ceux qui violeraient la donation sont menacés de la colère de diverses figures célestes ${ }^{61}$. Cette clause remarquable est d'un intérêt considérable du point de vue de la méthode de composition de l'acte et, comme pour la lettre synodale déjà discutée, il est possible de détecter une influence fécampoise sur ce texte. En fait, deux documents provenant de l'abbaye de Fécamp autour de l'an mil contiennent des passages semblables à ceux de l'acte de Mauger.

Le premier est la célèbre charte de fondation, que Mauger doit avoir connu comme moine de Fécamp ${ }^{62}$. L'anathème de cette charte est conçu comme la première partie de la malédiction de Mauger, dans la mesure où les transgresseurs sont menacés de la colère des figures célestes. Le professeur David Douglas a déjà montré comment le rédacteur de la charte fécampoise fonda sa liste des figures sur une litanie trouvée dans

55. Gesta Guillelmi, p. 86 (R. Foreville (éd.), p. 130).

56. Malmesbury, Gesta regum Anglorum, t. I, p. 494.

57. Perriers-sur-Andelle, dép. Eure, cant. Fleury-sur-Andelle.

58. Rouen, Arch. dép. Seine-Maritime, $14 \mathrm{H} 189$.

59. Rouen, BM, Y. 27 Omont 1405, p. 26-62. Voir également Rouen, Arch. dép. Seine-Maritime, G 1846, G 4014, G 8739, G 8740; Rouen, BM, Y. 7 Omont 369, fol. 1v-3, 81v-82v, 177, 188-19o, $191 \mathrm{v}$.

60. D. Bates, «The Conqueror's Adolescence», p. 11-12.

61. Voir l'édition critique de la charte ci-dessous (annexe II).

62. Fauroux, $n^{\circ} 4$, p. 74. 
deux sacramentaires français du IX $\mathrm{IX}^{\mathrm{e}}$ siècle ${ }^{63}$. Il semble que le rédacteur rouennais, qui travaillait sous les yeux de l'archevêque Mauger, s'appuya sur une source similaire, sauf qu'il a remplacé saint Hilaire et sainte Félicité, les saints représentant respectivement les confesseurs et les vierges, par deux figures plus importantes à l'abbaye Saint-Ouen, c'est-à-dire saint Ouen lui-même et sainte Agnès ${ }^{64}$.

Le deuxième texte fécampois est une formule d'excommunication, qui fut éditée par Edmond Martène d'après un manuscrit aujourd'hui perdu ${ }^{65}$. Parce que cette formule fut rédigée dans le premier quart du XIe siècle ${ }^{66}$, il est possible que Mauger en ait aussi eu connaissance quand il était moine. Comme dans les deux chartes déjà mentionnées, cette formule commence par une liste des figures célestes. Elle continue avec une liste de treize personnes maudites, dont sept se trouvent dans la liste analogue de la charte de Mauger ${ }^{67}$. Parmi celles qui se trouvent uniquement dans la liste archiépiscopale, la référence à Dacien, l'assassin de saint Vincent, est peut-être la plus intéressante. Il y avait une église rouennaise dédiée à l'honneur de ce saint (connue autrefois sous le nom de Saint-Vincent-sur-Rive), et bien qu'elle n'apparaisse dans les sources qu'au XII ${ }^{\mathrm{e}}$ siècle (le 21 avril 1169$)^{68}$, il est possible que la mention de Dacien dans l'acte archiépiscopal révèle la présence du culte de saint Vincent à Rouen pendant le XI ${ }^{\mathrm{e}}$ siècle, et peut-être une église en son honneur. En tout cas, la décision d'évoquer ces figures du christianisme naissant semblerait être une entreprise privée de la part du rédacteur de la charte ${ }^{69}$, et même peut-être de la part de l'archevêque Mauger, pour qui saint Vincent aurait été une figure spirituelle importante. Au minimum, la présence de tous ces noms révèle que soit l'archevêque Mauger, soit les hommes qui l'entouraient, avai(en)t une bonne connaissance du christianisme ancien.

Et pourtant, malgré la sophistication de cet anathème, il faut se demander dans quelles circonstances il fut rédigé. Il est possible que la nature furieuse de la malédiction reflète le chaos censé avoir régné à cette époque en Normandie, et la

63. D.C. Douglas, "The First Ducal Charter for Fécamp», in L'abbaye bénédictine de Fécamp. Ouvrage scientifique du XIII centenaire (658-1958), Fécamp, L. Durand, 1959, 4 vol., t. I, p. 52-53.

64. L'abbaye possédait les reliques de sainte Agnès (A. du Monstier, Neustria pia, Rouen, Jean Berthelin, 1663 , p. 59) et une copie de sa vie se trouve dans le célèbre manuscrit hagiographique, connu comme le Livre noir (Rouen, BM, Y. 41 Omont 1406, fol. 61v-83).

65. De antiquis ecclesiae ritibus, E. Martène (éd.), Bassano, 1788, 4 vol., t. II, p. 325.

66. L.K. Little, Benedictine Maledictions: Liturgical Cursing in Romanesque France, Ithaca, Cornell University Press, 1993, p. 8, n. 13 .

67. «Fiat habitatio eorum deserta, ignisque aeternus eorum sit cruciatus cum Chore, Datan et Abiron, Juda atque Pilato, Anania atque Sapphira, Nerone atque Decio, Herode, Juliano, Valeriano et Simone Mago cum quibus et his similibus secundum sua impia facta cruciatu perpetuo...» (De antiquis ecclesiae ritibus, p. 325).

68. L'église Saint-Vincent apparaît pour la première fois dans une charte de Rotrou, archevêque de Rouen (1165-1183). Pour une traduction de cet acte, aujourd'hui perdu, qui traite de la partie de l'église appartenant à l'abbaye de Saint-Ouen de Rouen, voir F. Farin, Histoire de la ville de Rouen, $3^{\mathrm{e}}$ éd., Rouen, L. Du Souillet, 1731, 2 vol., t. II, $4^{\mathrm{e}}$ partie, p. 107.

69. Le professeur Douglas soutient que ce fut le cas pour le rédacteur de la charte fécampoise (D.C. Douglas, «The First Ducal Charter...», p. 53). 
mesure dans laquelle les autorités ecclésiastiques s'efforçaient de défendre leurs possessions. Mais il n'est pas impossible que l'anathème ne représente qu'un simple intérêt de la part de l'archevêque pour des questions liturgiques, de la même façon que le rédacteur du cartulaire de Christ Church de Cantorbéry, qui travailla sous les yeux de Lanfranc, portait un intérêt obsessionnel aux malédictions ${ }^{70}$. Même si on considère l'anathème comme une tentative de défendre une possession ecclésiastique, il est frappant de voir Mauger, "le spoliateur», agissant comme un défenseur de l'Église. Ce fait doit donc conduire à reconsidérer les charges de spoliation lancées contre l'archevêque. Les sources diplomatiques et narratives montrent que ses prédécesseurs, les archevêques Hugues (942-989) et Robert, aliénèrent des biens de la cathédrale ${ }^{71}$, et même ceux des abbayes voisines ${ }^{72}$, en faveur de leurs parents. Puisque le frère de Mauger était le puissant comte de Talou, on s'attendrait à trouver des biens aliénés par l'archevêque en sa faveur, mais aucune charte ne le prouve. Les chroniqueurs ne donnent également aucune preuve substantielle à l'appui de leurs accusations. Guillaume de Poitiers réprouva l'attitude de l'archevêque parce qu'il offrait « une table regorgeant d'abondance et de richesse ${ }^{73}$, mais quelques années plus tard, Orderic Vital approuva la générosité semblable de Foucher, évêque de Lisieux ${ }^{74}$. Louis Violette émit l'hypothèse que la spoliation de Mauger fut peut-être limitée aux trésors de la cathédrale ${ }^{75}$, comme le suggèrent les Actes des archevêques ${ }^{76}$, mais la présence dans la bibliothèque du XII ${ }^{e}$ siècle du bréviaire associé à Richard de Saint-Vanne, sans doute un objet de grande valeur, suggère le contraire. Il est même possible que l'archevêque ait augmenté les biens de la cathédrale. Le tonlieu des Andelys ${ }^{77}$, perçu par les ministres de l'archevêque ( $a$ ministris meis), ne figure pas parmi les biens de la cathédrale énumérés dans deux chartes de l'archevêque Robert ${ }^{78}$, mais c'est exactement l'exemption de ce tonlieu qui est accordée aux moines de Saint-Père de Chartres par l'archevêque Mauger ${ }^{79}$.

70. R. Fleming, "Christ Church Canterbury's Anglo-Norman Cartulary», in Anglo-Norman Political Culture and the Twelfth-Century Renaissance, C. Warren Hollister (dir.), Woodbridge, The Boydell Press, 1997, p. 102-103.

71. R. Allen, "The Acta archiepiscoporum Rotomagensium... ", p. 38 ; Fauroux, ${ }^{\circ}$ 10; Bates, RRAN William I, $\mathrm{n}^{\circ} 230$; P. Bauduin, La première Normandie ( $X^{e}-X I^{e}$ siècles): sur les frontières de la haute Normandie: identité et construction d'une principauté, Caen, Presses universitaires de Caen (Bibliothèque du Pôle universitaire normand), 2004, p. 330.

72. Annales de l'abbaye Saint-Pierre-de-Jumièges. Chronique universelle des origines au XIII siècle, J. Laporte (éd.), Rouen, Lecerf, 1954, p. 84; Fauroux, $\mathrm{n}^{\circ} 201$.

73. Gesta Guillelmi, p. 86 (R. Foreville (éd.), p. 130).

74. $O V$, t. V, p. 322.

75. L. Violette, L'Église métropolitaine de Rouen pendant la première période normande ( $X^{e}-X I^{e}$ siècles), thèse de doctorat, Université de Paris X, 1994, 2 vol. (dactyl.), t. I, p. 41.

76. R. Allen, "The Acta archiepiscoporum Rotomagensium... ", p. 38.

77. Les Andelys, dép. Eure, ch.-1. de canton.

78. Fauroux, $\mathrm{n}^{\circ}$ 66-67.

79. Cartulaire de l'abbaye de Saint-Père de Chartres, B. Guérard (éd.), t. I, n XLIX, p. 176-177. 
Il n'y a guère de preuves à l'appui des charges selon lesquelles Mauger endommagea sa cathédrale. Bien que les indices archéologiques indiquent un ralentissement ou un arrêt des travaux sur le chantier de Rouen après la mort de l'archevêque Robert en $1037^{80}$, il est possible que les chapiteaux attribuables aux années 1050-1060, qui ont été trouvés dans les fondations des piliers de la nef gothique ${ }^{81}$, puissent avoir été réalisés sous Mauger. La courte période entre l'élection de l'archevêque Maurille en 1055 et l'achèvement des travaux en 1063 suggère aussi que Mauger n'endommagea pas le bâtiment inachevé, et même s'il n'apporta aucune contribution à l'infrastructure physique de la cathédrale (comme d'autres évêques normands du XI $\mathrm{XI}^{\mathrm{e}}$ siele) ${ }^{82}$, il semble qu'il améliora le fonctionnement du chapitre cathédral. Le décanat, par exemple, fut probablement établi par l'archevêque Robert ${ }^{83}$, mais c'est seulement pendant l'archiépiscopat de Mauger que nous pouvons constater quelqu'un dans l'exercice de cette dignité. Il semble que la fonction du cancellarius fut également instituée par l'archevêque ${ }^{84}$, ce qui indique peut-être les origines d'une chancellerie épiscopale. Mauger fut aussi accompagné par un chambellan, qui s'appelait Godebald ${ }^{85}$.

À la différence de ses premières années, nous ne savons presque rien de la dernière partie de la carrière de Mauger. En 1050, l'archevêque est présent à Lyons-la-Forêt, où il est témoin de la charte de fondation de l'abbaye de Saint-Évroult ${ }^{86}$. L'année suivante, Mauger attesta encore deux chartes en faveur de Saint-Wandrille, qui subsistent encore en original et portent les croix autographes de l'archevêque ${ }^{87}$. Bien qu'il ait tenu un synode à Rouen, quelques années auparavant, afin de condamner la simonie, Mauger ne participa pas au concile de Reims en octobre 1049. Cinq de ses suffragants s'y rendirent, et par leur intermédiaire l'archevêque de Rouen approuva au moins tacitement le veto mis par Léon IX au projet de mariage entre le duc Guillaume et Mathilde de Flandre ${ }^{88}$. Une tradition du Bec du XII ${ }^{\mathrm{e}}$ siècle prétend

80. M. Baylé, «Les évêques et l'architecture normande au XI ${ }^{e}$ siècle», in Les évêques normands du XIe siècle (Actes du colloque de Cerisy-la-Salle, 30 septembre-3 octobre 1993), P. Bouet et F. Neveux (dir.), Caen, Presses universitaires de Caen, 1995, p. 156.

81. M. Baylé, Les origines et les premiers développements de la sculpture romane en Normandie, $\mathrm{n}^{\circ} 100$ bis de la revue Art de Basse-Normandie, 1992, p. 116-117.

82. Le grand évêque réformateur, Jean d'Ivry, par exemple, semble n'avoir rien apporté à la construction de la cathédrale d'Avranches pendant qu'il était évêque (R. Allen, «"A Proud and Headstrong Man": John of Ivry, Bishop of Avranches and Archbishop of Rouen, 1060-79», Historical Research, t. LXXXIII, 2010, p. 201).

83. Spear, The Personnel, p. 200.

84. Osbern le doyen et Fulbert cancellarius se trouvent dans Cartulaire de l'abbaye de Saint-Père de Chartres, B. Guérard (éd.), t. I, n XLIX, p. 176-177.

85. Bates, RRAN William $\mathrm{I}, \mathrm{n}^{\circ} 217$.

86. Fauroux, $\mathrm{n}^{\circ} 122$.

87. Rouen, Arch. dép. Seine-Maritime, $16 \mathrm{H} \mathrm{27}$; Paris, BnF, lat. 16738, planche 5. Les textes sont édités dans Fauroux, $\mathrm{n}^{\circ}$ 124, 126. Les croix de Mauger sont assez nettement formées, ce qui n'est pas le cas de celles faites sur ces mêmes chartes par d'autres évêques et laïques, ce qui suggère que l'archevêque avait l'habitude d'écrire avec une plume.

88. M. de Boüard, Guillaume le Conquérant, p. 169. 
que telle fut l'attitude de Lanfranc, alors prieur de l'abbaye ${ }^{89}$, et l'approbation tacite de Mauger est peut-être le fond de vérité sur lequel fut brodée plus tard la légende selon laquelle l'archevêque aurait menacé d'excommunier le duc Guillaume à cause de son mariage consanguin ${ }^{90}$.

On ne sait pas très bien pourquoi Mauger n'assista pas au concile de Reims. Si on se fonde sur l'étude consacrée aux privilèges d'exemption de Jean-François Lemarignier, c'est en 1049 que Mauger commença à être «systématiquement écarté» de l'abbaye de Fécamp par l'abbé Jean de Ravenne ${ }^{91}$, une déclaration qui laisse entendre que l'archevêque avait commencé à perdre la maîtrise de sa province. Mais pour mieux comprendre cette partie de l'épiscopat de Mauger, il faut réexaminer la source sur laquelle reposent les conclusions de cet éminent spécialiste. Il s'agit d'une sorte de liste des ordinations, qui se trouve dans un texte traditionnellement appelé «Appendice de Saint-Gabriel ${ }^{92}$. Ces ordinations furent faites par divers évêques étrangers, invités à Fécamp par l'abbé Jean. Selon Lemarignier, la première ordination eut lieu en 1049, parce qu'elle fut faite par Hugues d'Eu, qui devint évêque de Lisieux en cette année, et parce que l'homme qu'il ordonna diacre devint évêque de Bayeux avant avril 1050. La date du début de l'épiscopat d'Hugues d'Eu est fondée sur le récit d'Anselme de Saint-Rémy, qui affirme que l'évêque Herbert de Lisieux, le prédécesseur d'Hugues, se trouvait parmi la délégation des évêques normands au concile papal ${ }^{93}$. Mais deux sources méconnues suggèrent que ce texte rémois, qui est la première source depuis une charte de 1035 à faire allusion à l'évêque Herbert ${ }^{94}$, se trompe. La première est l'obituaire de la cathédrale de Lisieux, qui situe le décès d'Herbert au 16 juillet ${ }^{95}$. Cette date est incompatible avec la venue d'Herbert à Reims, car si l'évêque mourut le 16 juillet 1049, il ne peut pas avoir assisté à un concile tenu en octobre de cette même année. La deuxième source est la charte de l'archevêque Mauger et de son frère pour Saint-Ouen de Rouen. Comme nous l'avons déjà vu, cet acte fut rédigé en partie double et à deux mains, sur un seul parchemin. Les témoins du premier acte et tous ceux du second acte furent écrits en même temps en caroline minuscule par le

89. Vita Lanfranci, p. 675-676.

90. Malmesbury, Gesta regum Anglorum, t. I, p. 494; Wace, The Roman de Rou, p. 198.

91. J.-F. Lemarignier, Étude sur les privilèges d'exemption et de juridiction ecclésiastique des abbayes normandes depuis les origines jusqu'en 1140, Paris, Picard, 1937, p. 40.

92. L. Musset, "Notules fécampoises", Bulletin de la Société des Antiquaires de Normandie, t. LIV, 1957, p. 596-597.

93. "Anselme de Saint-Rémy: histoire de la dédicace de Saint-Rémy», J. Hourlier (éd.), in La Champagne bénédictine: contribution à l'année Saint-Benoît (480-1980), Reims, Académie nationale de Reims, 1981, p. 236.

94. Bates, RRAN William $I, \mathrm{n}^{\circ} 212$.

95. «Obitus domni Hesberti episcopi Lexoviensis», Paris, BnF, nouv. acq. lat. 1778, fol. 65v; Caen, Arch. dép. Calvados, F 5557, p. 191. Ce nécrologe enregistre les décès de plusieurs évêques lexoviens, dont les dates peuvent être corroborées par d'autres sources (voir, par exemple, les entrées sur Hugues d'Eu, Gilbert Maminot, Foucher, Jean, Arnoul et Raoul de Varneville, Paris, BnF, nouv. acq. lat. 1778, fol. 18v, 51, 66, $74,76,79)$. 
deuxième scribe. Parmi les témoins du second acte, se trouve la souscription d'Hugues d'Eu, évêque de Lisieux. Normalement, la charte devrait être datée à partir de 1049, mais parmi les témoins du premier acte se trouve la souscription de Gradulphe, abbé de Saint-Wandrille, décédé le 6 mars $1047^{96}$, et parmi ceux du second on trouve la souscription de Guillaume Busac, le frère d'Hugues d'Eu, qui se rebella vers 1047 / 1048 et fut exilé peu après ${ }^{97}$.

Quelle est l'importance de cela pour notre compréhension de ces ordinations fécampoises? Tout d'abord, il paraît évident que Hugues d'Eu fut évêque de Lisieux avant le 6 mars $1047^{98}$, et certainement avant octobre 1049. L'ordination faite par lui à Fécamp pourrait donc être datée dès 1047, et non strictement en 1049, comme l'a suggéré Lemarignier. Il est même possible que cette première ordination eut lieu dans l'année du concile de la Trêve de Dieu, et que cet acte ne représente pas une rupture entre Mauger et l'abbaye de Fécamp, mais plutôt une politique archiépiscopale par laquelle l'évêque Hugues aida son archevêque, qui s'occupait des préparatifs du concile de paix, avec les fonctions épiscopales de son diocèse. Selon Elisabeth van Houts, c'est ce même concept qui aurait sous-tendu l'élection de Gradulphe de Saint-Wandrille comme le vicarius, voire adjoint, de Mauger ${ }^{99}$. Hugues aurait certainement été un bon choix pour occuper un rôle semblable, parce qu'il était non seulement le cousin de l'archevêque Mauger, mais il se trouvait aussi, selon la charte de Saint-Ouen, parmi ses fidèles ${ }^{100}$. Certes, l'abbaye de Fécamp continua de bénéficier du privilège d'inviter les évêques étrangers à effectuer des ordinations après celle que fit Hugues. Mais plutôt que de critiquer l'archevêque Mauger, il est important d'admettre qu'il y a des facteurs autres qu'une perte de maîtrise à l'origine de cette indépendance bienfaisante.

Même si ces conclusions ne sont pas fondées, la chute ultime de Mauger ne serait pas causée par ses relations ecclésiastiques. Au contraire, son destin serait scellé par ses parents laïques, et en particulier par son frère Guillaume, qui au début de l'été 1053 rompit avec le duc. La cause de sa révolte est discutée, mais il est probable que derrière ce complot se cache une divergence de fond sur la politique menée par le duc depuis la victoire du Val-ès-Dunes, par laquelle les Richardides furent lentement écartés de la cour ducale ${ }^{101}$. Malheureusement, on ne sait pas quel rôle joua l'archevêque de Rouen dans la rébellion de son frère. Parmi les chroniqueurs normands, seul Orderic

\footnotetext{
96. Gazeau, Normannia monastica, t. II, p. 335.

97. Gesta Normannorum ducum, t. II, p. 10, n. 4 et p. 128, n. 205; P. Bauduin, La première Normandie..., p. 297.

98. On peut faire remonter le début de l'épiscopat d'Hugues vers 1046, si on se réfère à une charte ducale où il apparaît aux côtés de Hugues, évêque d'Évreux (1015-v. 1046) (Fauroux, n 110), ou à la chronique de Saint-Pierre-sur-Dives, qui soutient que la fondation de cette abbaye eut lieu en 1046, pendant l'épiscopat d'Hugues de Lisieux (GC, t. XI, Instr., col. 155A-B).

99. E.M.C. van Houts, «Historiography and Hagiography at Saint-Wandrille: the "Inventio et Miracula sancti Vulfranni”" ", ANS, t. XII, 199o, p. 246.

100. Annexe II.

101. P. Bauduin, La première Normandie..., p. 309-310.
} 
Vital raconte comment le comte de Talou reçut le soutien de son frère ${ }^{102}$, mais ce récit n'est guère convaincant. Contrairement à son prédécesseur, l'archevêque Robert, aucune source ne laisse supposer que Mauger s'illustra sur les champs de bataille ${ }^{103}$. Le contexte diplomatique suggère également que le comte de Talou ne reçut aucun soutien de son frère, puisqu'on peut encore voir l'archevêque aux côtés du duc le 25 décembre $1053 / 54^{104}$, tandis que son frère est déjà en exil.

Mais même si aucun autre Richardide, y compris Mauger, ne paraît s'être joint au complot du comte de Talou, le duc Guillaume fut sans doute pleinement conscient de la menace constituée par ce lignage fraternel. Et c'est peut-être parce que l'archevêque de Rouen approuva au moins tacitement les actions de son frère que le duc décida de le déposer. Le concile finalement convoqué à cette fin fut un événement bien orchestré ${ }^{105}$. La réunion eut lieu dans la cathédrale de Lisieux et le duc lui-même ainsi que tous les évêques normands y assistèrent, tout comme Ermenfroi, évêque de Sion, légat du pape ${ }^{106}$. Nous n'avons pas besoin d'insister sur la ressemblance avec la déposition de Stigand, archevêque de Cantorbéry (1052-1070), une quinzaine d'années plus tard. Une fois prononcée sa destitution, Mauger, l'archevêque discrédité, fut remplacé par Maurille, un moine quasi-ermite sans réseau familial normand, et comme pour souligner que le lignage de Mauger n'était plus pertinent, il fut condamné au cours du concile par son cousin et son fidèle, Hugues d'Eu, évêque de Lisieux ${ }^{107}$. Pour finir, l'archevêque fut relégué à Guernesey, une île que, selon les Actes des archevêques de Rouen, le duc «donna» (dedit) à Mauger ${ }^{108}$. Ce choix de mots est plein d'intérêt, parce qu'il semble

102. OV, t. IV, p. 84. L'accusation d'Orderic est souvent acceptée par les spécialistes (D.C. Douglas, «The Norman Episcopate before the Norman Conquest », Cambridge Historical Review, t. XIII, 1957, p. 104; D. Bates, Normandy before 1066, p. 209; P. Bouet, M. Dosdat, «Les évêques normands...», p. 19-20).

103. Gesta Normannorum ducum, t. II, p. 48.

104. Fauroux, $\mathrm{n}^{\circ} 133$.

105. La date du concile est discutée. Pour les arguments en faveur de l'an 1055, voir M. de Boüard, «Notes et hypothèses sur Maurille, moine de Fécamp, et son élection au siège métropolitain de Rouen ", in L'abbaye bénédictine de Fécamp. Ouvrage scientifique du XIII centenaire (658-1958), Fécamp, L. Durand, 1959, 4 vol., t. I, p. 89. Pour ceux en faveur de l'an 1054, voir H.E.J. Cowdrey, «Bishop Ermenfrid of Sion and the Penitential Ordinance following the Battle of Hastings ", JEH, t. XX, 1969, p. 226-227; R. Foreville, "The Synod of the Province of Rouen in the Eleventh and Twelfth Centuries", in Church and Government in the Middle Ages: Essays Presented to C.R. Cheney, C.N.L. Brooke, D.E. Luscombe, G.H. Martin et D. Owen (dir.), Cambridge, Cambridge University Press, 1976, p. 23 n. c. Notons que les annales normandes enregistrent le concile sous l'an 1055: "Chronicon Rotomagense», in Novae bibliothecae manuscriptorum librorum, P. Labbé (éd.), Paris, 1657, 2 vol., t. I, p. 366; «Historia annalis brevis in monasterio sancti Stephani Cadomensis ", in Scriptores rerum Gestarum Willelmi Conquestoris, J. Giles (éd.), Londres, 1845, p. 165; "Annales Uticenses», in Orderic Vital, Ecclesiasticae Historiae libri XIII, A. Le Prévost (éd.), Paris, Société de l'histoire de France - J. Renouard, 1838-1855, 5 vol., t. V, p. 157; Annales de Jumièges, J. Laporte (éd.), p. 56 ; La Haye, Koninklijke Bibliotheek, ms. 128 E 14, fol. 10 (annales de Saint-Wandrille).

106. R. Allen, «The Acta archiepiscoporum Rotomagensium... », p. 38-39; Gesta Guillelmi, p. 88 (R. Foreville (éd.), p. 132); OV, t. III, p. 86; Malmesbury, Gesta regum Anglorum, t. I, p. 494.

107. Gesta Guillelmi, p. 92 (R. Foreville (éd.), p. 138).

108. R. Allen, "The Acta archiepiscoporum Rotomagensium... », p. 39. 
se rapporter à une concession résultant des négociations par lesquelles l'archevêque, qui jugea que sa position était intenable, quitta son office volontairement. Cette idée est partiellement confirmée par Guillaume de Jumièges, qui raconte comment Mauger «rendit (reddidit) au duc son archevêché » ${ }^{109}$. Au minimum, la décision de bannir Mauger à la périphérie occidentale du duché suggère que le duc cherchait à garder l'archevêque éloigné de son frère, qui se réfugia à la cour du comte de Boulogne ${ }^{110}$, et que Guillaume voulait prévenir une collusion dont Mauger n'avait pas été initialement coupable, mais que l'ancien archevêque pourrait maintenant être prêt à envisager.

Il semble que la condamnation de l'archevêque Mauger provint donc d'un sentiment de «culpabilité par association». Bien que les chroniqueurs insinuent que Mauger fut écarté parce qu'il avait négligé son office ecclésiastique, aucun récit du concile ne subsiste à l'appui de ces accusations. De plus, les preuves examinées au cours de cet article montrent que ces jugements de la fin du $\mathrm{XI}^{\mathrm{e}}$ ou du début du XII ${ }^{\mathrm{e}}$ siècle méritent d'être nuancés. La carrière de Mauger fut, en effet, caractérisée par des réalisations pour lesquelles les grands réformateurs, comme Lanfranc, furent loués: conciles, entreprises pédagogiques, patronage monastique. Mais dès que sa réputation fut ternie au concile de Lisieux, un vrai procès pour l'exemple, il y eut peu de chance que ses réussites fussent reconnues par les chroniqueurs monastiques. Leurs travaux furent fortement influencés par le nouveau modèle épiscopal imposé par la réforme grégorienne, dont Maurille en Normandie et Lanfranc en Angleterre furent les figures les plus exemplaires: de ce fait, et comme Pierre Bouet l'a déjà fait observer en parlant de la carrière d'un autre archevêque dénigré, Hugues de SaintDenis, «peu de prélats antérieurs à la réforme trouvaient grâce aux yeux des auteurs ecclésiastiques partisans de l'action engagée par la papauté, même si leur action avait été alors bénéfique pour l'Église normande » ${ }^{111}$. Bien sûr, Mauger n'allait jamais être comme ceux qui lui succédèrent. Mais si nous fixons exclusivement notre attention sur les hommes du calibre de Lanfranc, notre compréhension de cette époque risque d'être conditionnée par les chroniqueurs monastiques. Il y a cinquante ans, David Douglas a constaté comment la restauration des institutions ecclésiastiques dans la Normandie ducale fut due à de nombreux facteurs ${ }^{112}$. Alors que ce colloque est dédié à la carrière de l'un des personnages les plus importants de cette restauration, notons que les jugements que nous portons sur l'archevêque Mauger et sur ceux qui lui ressemblent doivent tenir compte de réussites plus importantes que ne le suggère la documentation disponible souvent négative.

Richard AlLEN

St. Peter's College, Oxford

109. Gesta Normannorum ducum, t. II, p. 130.

110. Ibid., p. 104.

111. Chroniques latines du Mont Saint-Michel (IX ${ }^{e}-X I I^{e}$ siècle), P. Bouet et O. Desbordes (éd.), Caen, Presses universitaires de Caen (Les manuscrits du Mont Saint-Michel. Textes fondateurs; 1), 2009, p. 162.

112. D.C. Douglas, William the Conqueror..., p. 124. 


\section{Annexe I. \\ Lettre synodale de l'archevêque Mauger, vers 1045}

\section{A. Original perdu.}

B. Manuscrit perdu de date inconnue du Mont Saint-Michel. - C. Manuscrit perdu de Jacques Sirmond (d'après $B$ ).

a. P. Labbé (éd.), Concilia..., t. IX, col. 1047-1048 (d'après C). — b. Sanctae Rotomagensis ecclesiae concilia ac synodalia decreta, J.-F. Pommeraye (éd.), Rouen, 1677, p. 66 (aucune source). - c. Concilia Rotomagensis provinciae, G. Bessin (éd.), Rouen, 1707, p. 40-41 (d'après $C$ ). $-d$. Acta conciliorum et epistolae decretales, ac constitutiones summorum pontificum, J. Harduin (éd.), Paris, 1714-1715, 11 vol., t. VI ( $1^{\text {re }}$ partie), col. 1011-1012 (d'après $C$ ). - e. Sacrosancta concilia ad regiam editionem exacta quae olim quarta parte prodiit auctior, N. Coleti (éd.), Venise, 1728-1733, 23 vol., t. XI, col. 1417-1418 (d'après $C$ ). - f. Sacrorum conciliorum nova, et amplissima collectio, G. Mansi (éd.), Florence, 1759-1793, 31 vol., t. XIX, col. 751-752 (d'après C). - g. J. de Caulet, Dissertation à l'occasion des actes de l'assemblée générale du clergé de France de 1765, sur la religion, Grenoble, 1767-1768, 2 vol., t. II, p. 106 n. a (d'après c).

$a$

Fratribus nostris, $\mathrm{ac}^{(\mathrm{a})}$ comprovincialibus episcopis, et cæteris orthodoxis fidelibus ${ }^{(\mathrm{b})}$, Malgerius sanctæ Rotomagensis ecclesiæ præelectus episcopus, Hugo Ebroicacensis ${ }^{(c)}$ sedis episcopus, Rotbertus ${ }^{(\mathrm{d})}$ Constantiæ $^{(\mathrm{e})}$ sedis episcopus, et omne concilium, in Domino salutem. Quoniam, sanctissimi fratres, sanctam matrem ecclesiam a primo sui honoris et tranquillitatis statu penitus immutatam videmus, partim sublatis e vita bonis principibus, partim ignaris et imbecillibus successoribus, sed et magis peccatis nostris exigentibus: placuit sacerdotalem inter nos fieri conventum, ut salutifera collatione, in quantum divina nobis gratia inspiraverit, quod male a nobis erratum est, corrigamus ; ${ }^{(f)}$ quod recte et sobrie factum, stabiliter teneamus.

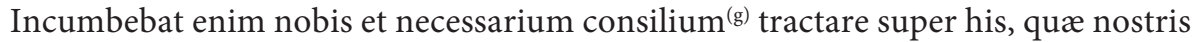
temporibus ab inimicis ecclesia sancta ${ }^{(\mathrm{h})}$ patitur. Sed quia, ut ait beatus Gregorius, ordo erectionis $^{(i)}$ in bono iste est, ut primum contra nos, et postmodum contra malos erigamur: quod a nobis constat admissum, a nobis quoque primum judiciali sententia expietur. Et licet de re hujusmodi, quam salubri ordinatione constituere volumus, præcedentium patrum prisca autoritas ${ }^{(j)}$ nequaquam silverit: tamen quia multi inter nos sunt, qui aut exiguam, aut pene ${ }^{(\mathrm{k})}$ nullam rectæ ${ }^{(\mathrm{l})}$ eruditionis notitiam contigerunt, necessarium duximus ea quæ a sanctis patribus nobis tradita sunt in medium recensere. Videlicet. 
(a) et $b c$. - (b) fidelibus omis $b c$. - (c) Ebroicensis $b c$. - (d) Robertus $b c$. (e) Constancicae $b$. - (f) et ajouté $b c$. - (g) concilium $b c$. - (h) sancta ecclesia $b c$. - (i) directionis $b c$. - (j) auctoritas $d g$. - (k) pæne $d$. - (l) rectæ omis bc.

immutatam videmus] «...vel doctrina vel vetustate immutatam videmus», Cicéron, De Divinatione, A.S. Pease (éd.), Urbana, Ill., 1920-1923, p. 464.

peccatis nostris exigentibus] «Cum ergo virtutem nostrae patientiæ flagella transeunt, valde metuendum est ne, peccatis nostris exigentibus... ", S. Gregorii Magni Moralia in Iob, M. Adriaen (éd.), Turnhout, Brepols (Corpus Christianorum. Series Latina; 143, 143A, 143B), 1979-1985, t. II, lib. XIV, par. XXXVII, p. 725.

sacerdotalem inter nos fieri conventum] «... sacerdotalem inter nos fieri debere conventum...», Concile de Braga I (561), praef., G. Mansi (éd.), Sacrorum..., t. IX, col. 773 .

salutifera collatione] «... inter se salutifera collatione requirunt...», Concile de Braga I (561), praef., G. Mansi (éd.), Sacrorum..., t. IX, col. 773.

recte et sobrie] «... ut caste, recte et sobrie vivant», Concile de Merida (666), c. 4, G. Mansi (éd.), Sacrorum..., t. XI, col. 78.

ut ait Gregorius ... malos erigamur] «Ordo quippe erectionis in bono iste est ut primum contra nos, et postmodum contra malos erigamur», Moralia in Iob, t. II, M. Adriaen (éd.), lib. XIV, par. XXIX, p. 718.

Et licet ... nequaquam silverit] «Licet de re hujusmodi, quam constituere salubri ordinatione decrevimus, prisca autoriatas nequaquam silverit... », Concile de Lérida (546), c. 16, G. Mansi (éd.), Sacrorum..., t. VIII, col. 614.

aut exiguam ... notitiam contigerunt] «...aut exiguam, aut pene nullam rectæ eruditionis notitiam contigerunt», Concile de Braga I (561), praef., G. Mansi (éd.), Sacrorum..., t. XI, col. 773 . 


\section{ANNEXe II}

[v. 1046-1047, 6 mars]

L'archevêque Mauger et son frère Guillaume, comte d'Arques, donnent Perriers-surAndelle, avec ses dépendances, à l'abbaye Saint-Ouen de Rouen. L'archevêque fulmine l'anathème contre ceux qui oseraient enfreindre cette donation.

A. Original, parchemin, larg. $515 \mathrm{~mm}$ x haut. $700 \mathrm{~mm}$, réglé à la pointe sèche, 27 lignes, dont 15 lignes de texte, en caractères allongés, et 12 lignes en minuscule caroline, aucune trace de scellement, Rouen, Arch. dép. Seine-Maritime, $14 \mathrm{H} 189^{113}$.

B. Copie partielle du XIII ${ }^{\mathrm{e}}$ siècle, Rouen, Arch. dép. Seine-Maritime, 14 H 189. - C. Copie partielle du XVII ${ }^{\mathrm{e}}$ siècle, Rouen, Arch. dép. Seine-Maritime, $14 \mathrm{H} 189$ (d'après $B$ ). - D. Copie partielle du XVII ${ }^{\mathrm{e}}$ siècle, Rouen, Arch. dép. Seine-Maritime, $14 \mathrm{H} 189$ (d'après $B$ ). - E. Copie du XVIII e siècle par J.-N. Lenoir, Paris, BnF, coll. Moreau, vol. 22, fol. 151r-v (d'après $A$ ). $-F$. Copie partielle du XVIII ${ }^{e}$ siècle par J.-N. Lenoir, Château de Semilly, coll. Mathan, vol. 76, $2^{\mathrm{e}}$ partie, p. 185 (d'après $A$ ). - G. Copie du XVIII siècle, Paris, BnF, nouv. acq. lat. 1246, fol. 193r-v (d'après $A$ ). - H. Copie du XIX siècle, Paris, BnF, nouv. acq. lat. 1243, fol. 116r-v (d'après $A$ ). - I. Copie du XIX ${ }^{\mathrm{e}}$ siècle par L. Delisle, Paris, BnF, nouv. acq. fr. 21815, fol. 267

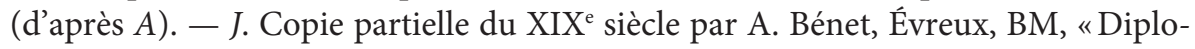
matique des ducs de Normandie», carton 11, fol. 699-700 (d'après $A)^{114}$. - K. Copie partielle du XX siècle par G. de Beausse, Caen, Arch. dép. Calvados, F 5277 (d'après A).

a. D. Gurney, The Record of the House of Gournay, Londres, 1848-1858, 4 vol., t. I, p. 43, Appendix III, $\mathrm{n}^{\circ} 2$ (d'après $A$ ). - b. A. Le Prévost, Mémoires et notes pour servir à l'histoire du département de l'Eure, L. Delisle (éd.), Évreux, Imprimerie d'Auguste Hérissey, 1862-1869, 3 vol., t. II, p. 523 (d'après $A$ ). - c. Fauroux, n 112 (d'après $A$, partiel).

Indique: Paris, BnF, lat. 13816, fol. 126 - A. du Monstier, Neustria pia, p. 22 A. Bénet, "Diplomatique des ducs», carton 2, t. II, fol. $562-G C$, t. XI, col. $29-$ D. Bates, «The Conqueror's Adolescence», p. 11-12.

Note. Les bornes chronologiques de cet acte sont déterminées par l'épiscopat de Guillaume, évêque d’Évreux, et la mort de Gradulphe, abbé de Saint-Wandrille. Les signes $\backslash$ / indiquent un mot interligné.

113. Mentions dorsales: De Pirariis (XI $\left.{ }^{\mathrm{e}} \mathrm{s}.\right)$; Carta Willelmi Archensis comitis et Malgeri archiepiscopi fratris ejus et de villa qui dicitur Periers (XII ${ }^{\mathrm{e}} \mathrm{s}$.); cum copia (XIII ${ }^{\mathrm{e}} \mathrm{s}$.).

114. Cette copie est la même que ms. H dans l'édition de Fauroux. 
Ad honorem Domini ac salvatoris nostri Jhesu Christi Sanctae Matris Aecclesiæ antecessores nostri pullulante seculo alii/ $/ /^{1}$ predia alii ornamenta plurimi varia intulerunt beneficia, quatinus laus Dei et exultatio absque interpolatione $\mathrm{e}^{(\mathrm{a})}$ haberetur $/ /^{2}$ in ea, et

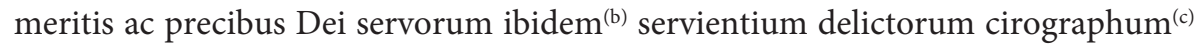
deleretur in secula. Nunc igitur labente//3 in precipitium seculo, contemporales ${ }^{(\mathrm{d})}$ nostri rabie diabolica instincti non solum priscos refugiunt immitari datores; sed et furtim $/ / 4$ satagunt et aperte data vi diripere, et ęcclesiam Dei per quam sunt regenerati et in Christo nutriti incessanter ${ }^{(e)}$ adnichilare. Sed quamvis $/ / 5$ mors perhennis faucibus non nullos tetris degluciatos jam teneat, et adhuc restent quos totius auctor malitię non sinit adquies $/ /{ }^{6} \mathrm{cere}^{(\mathrm{f})}$ donec aeternaliter absorbeat, tamen sunt quam plurimi Dei benivolentia $^{(\mathrm{g})}$ ammoniti quos sponsam Christi scilicet supradictam//7 aecclesiam, in quantum suppetit facultas vita malorum honorare non retardat. Ex quibus ego

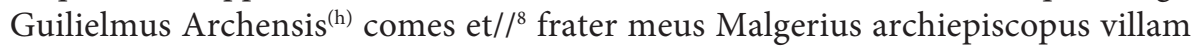
quę dicitur Perers ${ }^{(i)}$ sitam super fluvium qui dicitur Andela cum appendiciis suis per voluntatem $/ /{ }^{9}$ matris meę Paveię annuente Guilielmo Normannorum comite sancto Petro sanctoque Audoeno et monachis inibi Deo servientibus perhenniter ${ }^{(j)} / /^{10}$ tradimus, pro animabus parentum nostrorum et nostris, Ricardi videlicet patris et fratrum nostrorum junioris Ricardi necnon et Rotberti $/ /{ }^{11}$ comitum, quatinus ${ }^{(\mathrm{k})}$ nostra illorumque memoria ibidem habeatur per seculorum secula. Et ne quis nostrorum heredum vel parentum seu aliquorum hominum sua $/ /^{12}$ dente diabolo huic donationi ${ }^{(1)}$ clamorem sive contradictionem inferat. Ex bonis sanctorum et substantia monachorum libras trecentas ${ }^{(\mathrm{m})} / /{ }^{13}$ denariorum accipimus ${ }^{(\mathrm{n})}$, et manibus nostris signo sanctę crucis hanc $\operatorname{kartam}^{(\mathrm{o})}$ firmamus, ut nobis Deus misericordiam suam hic et in euum tribuat, $/ /^{14}$ ac contradictorem hujus rei in inferni ${ }^{(\mathrm{p})}$ voraginem trudat ${ }^{(\mathrm{q})} . / /^{15}$

(crux) S. Gradulfi abbatis \Sancti Wandregesili/.//16

(crux) S. Willelmi ducis. (crux) S. Malgerii archiepiscopi. (crux) S. Rotb(er)ti episcopi $\backslash$ Constantię civitatis/. (crux) S. Willielmi comitis $\backslash$ Arcas/. (crux) S. Isemberti abbatis ISanctę Trinitatis/.//17

Ego Malgerius gratia Dei archiepiscopus cum auctoritate pie Matris Aecclesię quam Deo volente guberno hanc descriptionem fieri ratam omnimodo exopto, signumque sanctę crucis subter ass $/ /{ }^{18} \mathrm{cribo}$, et nomen meum ac nostrorum fidelium imprimi mando. Quatinus ut decet sic firma et inviolata hęc donatio perseveret. Quodsi aliquis huic dono quod absit et minime fore credimus//19 contrarius extiterit, his maledictionibus quę subter describuntur subiciatur. Maledictus sit ab omni potente Deo, maledictione qua maledictus est diabolus et angeli ejus, in igne perpetuo.//20 Maledicat eum sancta Dei genetrix Maria, nec habeat partem cum electis Dei positis ad dextram, sed cum reprobis jure ponendis ad sinistram. Maledicat eum sanctus Michahel cum omnibus ordinibus angelorum.//21 Maledicat eum sanctus Johannes baptista, omnesque patriarche et prophete. Maledicat eum sanctus Petrus cum ceteris apostolis. Maledicat eum sanctus Stephan(us) cum omnibus martyribus. Maledicat 
eum sanctus//22 Audoen(us) cum omnibus Christi confessoribus. Maledicat eum sancta Agnes cum omnibus virginibus. Omnis maledictio qua maledictus est Cain, Dathan et Abiron, Antiochus, Herodes, Pontius Pilat(us),//23 Judas domini traditor, Nero, Symon magus, Dioclitianus, Maximian(us), ac Datianus, veniat super eum. Sit pars illius cum omnibus iniquis ininferiori inferno, ubi ignis non extinguitur, nec vermis//24 moritur. Fiant dies ejus pauci et mali. Et in isto seculo ante oculos hominum pessime ac turpiter pereat, et infuturo lucerna illius extinguatur, et de libro vitę nomen ejus deleatur. Amen, amen. Fiat.//25

(crux) S. Willelmi \Ebroas/ episcopi. (crux) S. Johannis \abbati Sanctę Trinitatis/. (crux) S. Hugonis \Lisiacensis/ episcopi (crux) S. Willelmi \Dou/ (crux) S. Rotberti IDou/(crux) S. Gisleberti \filii Lotemer/ (crux) S. Gumfridi \dapiferi/ (crux) S. Rogerii Ifilii Hunfridi/ (crux) S. Willelmi \filii Osberni///26 (crux) S. Rogerii \Gomerei/ (crux) S. Rodulfi \Taison/ (crux) S. Rodulfi \filii Geraldi/ - S. Hugonis \Gornai/ (crux) S. Lanberti \filii Ricardi vicecomitis/ (crux) S. Hugonis \Britonis/ (crux) S. Warnerii Ide Metante/.

(a) interpollatione $B .-$ (b) servientibus ajouté $B .-$ (c) voveretur in barré avant deleretur B. - (d) cumtemporales (sic) B. - (e) insessanter B. - (f) acquiescere B. - (g) begnivolencia $B .-$ (h) Arcensis $B .-$ (i) Periez $B .-$ (j) et monachis ... perhenniter illisible $B$. - (k) que barré avant nostra $B .-(\mathrm{l})$ amo. barré avant clamorem $B .-(\mathrm{m})$ trescentas $B$. - (n) accepimus B. - (o) cartam B. - (p) ininferni B. - (q) B s'arrête ici. 